\title{
Physiological Consequences of a Peptide Cotransmitter in a Crayfish Nerve-Muscle Preparation
}

\author{
Cynthia A. Bishop, Jeffrey J. Wine, Frederic Nagy, and Michael R. O'Shea ${ }^{1}$ \\ Department of Psychology, Stanford University, Stanford, California 94305, and 'Department of Animal Biology, University \\ of Geneva, Geneva, Switzerland
}

\begin{abstract}
The pentapeptide proctolin is colocalized with a conventional, conductance-increasing neurotransmitter in 3 of 5 excitatory motoneurons that innervate a posture-related tonic flexor muscle of the crayfish. It is released from these neurons in response to nerve impulses. Nanomolar concentrations of proctolin superfused on the tonic flexor muscle act postsynaptically to potentiate tension generated by a given level of depolarization. Proctolin alone has no detectable effect on muscle tension, nor does it alter the resting membrane potential of the muscle. Proctolin produces no detectable effect on the EPSPS of the 1 proctolinergic motoneuron that was examined.

Neurally released proctolin can be selectively depleted from severed motor axons following prolonged, low-frequency stimulation; EPSPs reflecting conventional transmitter release are unaltered by this procedure. After proctolin depletion, tension generated by the motoneuron is greatly reduced.
\end{abstract}

Taken together, these results indicate that the peptide secondary transmitter in this neuromuscular preparation is an important contributor to the magnitude of tension generated by the motoneuron, but since its effect is dependent on the depolarizing EPSPs of the conventional neurotransmitter, it does not contribute to the temporal aspects of tension generation. These aspects are controlled exclusively by the conventional neurotransmitter.

It has been established that many neurons release multiple transmitters, but much remains to be learned about synaptic transmission in such cases. For example, we do not know if the mechanisms of release are identical for all transmitters, and we know little of how the postsynaptic actions of each transmitter are coordinated. Because of such questions, and because the behavioral significance of multiple transmitters is often obscure, we are developing a model system for studying the mechanisms and functions of multiple neurotransmitters in excitation-contraction coupling.

The system we are studying, which consists of 5 excitatory motoneurons, 1 inhibitory motoneuron, and approximately 40

\footnotetext{
Received July 21, 1986; revised Dec. 17, 1986; accepted Dec. 22, 1986.

This work was supported by a Muscular Dystrophy Association grant to J.J.W. and by NIH Grant 20557 to J.J.W. and C.A.B. We are grateful to J. Miller and G. Hagiwara for their excellent technical assistance.

Correspondence should be addressed to Cynthia A. Bishop, Department of

Psychology, Stanford University, Jordan Hall, Bldg. 420, Stanford, CA 94305.

aPresent address: Neurobiologie comparée, Place du D'B.-Peyneau, Universite de Bordeaux, 33120 Arcachon, France.

Copyright (c) 1987 Society for Neuroscience $0270-6474 / 87 / 061769-11 \$ 02.00 / 0$
}

muscle fibers, is part of a well-described postural control system in the crayfish abdomen (Kennedy and Takeda, 1965; Wine et al., 1974). The muscles are "slow," as opposed to twitch muscles, and the neurons fire tonically at various rates so that some degree of tension is usually present in the muscles.

In previous work (Bishop et al., 1984) we used immunohistochemistry and high-performance liquid chromatography (HPLC) to show that 3 of the motoneurons contain the pentapeptide proctolin (H-Arg-Tyr-Leu-Pro-Thr-OH). All 5 excitatory motoneurons produce conventional, conductance-increasing EPSPs. We hypothesized that proctolin was being released during nerve activity and was contributing in some way to tension generation in these muscles. We knew that proctolin is released by certain insect motoneurons, where it produces sustained increases in muscle tension withoul concomitant changes in membrane potential (Adams and O'Shea, 1983). In this paper, we demonstrate neural release of proctolin by identified crayfish motoneurons and depletion by repetitive stimulation of axons that are separated from their cell bodies but are otherwise healthy. We also begin the analysis of the postsynaptic effects of proctolin by showing that it makes a powerful contribution to muscle tension without any measurable effect on the conventional EPSPs. The work was made possible by several advantageous features of this system, including parallel innervation of the muscle with proctolinergic and nonproctolinergic neurons, and the long-term survival of conventional transmission by axons that have been separated from their cell bodies.

\section{Materials and Methods}

Animals. Crayfish, Procambarus clarkii, were obtained from commercial suppliers and maintained in laboratory tanks. Locusts, Schistocerca gregaria, used for the bioassay were kindly supplied by Dr. Corey Goodman (Dept. of Biology, Stanford University).

Bioassay for proctolin release. Proctolin release was monitored using an extremely sensitive and quantifiable bioassay, which depends upon proctolin's ability to modify the myogenic oscillations of a subset of muscle fibers within the main extensor muscle of the locust hindleg (O'Shea and Adams, 1981; O'Shea and Bishop, 1982). Proctolin, in femtomolar concentrations, increases the frequency of contractions in this small muscle bundle in a log-linear manner (O'Shea and Adams, 1981; Keshishian and O'Shea, 1985). In our experiments, a metathoracic leg of immature adult female specimens of the locust $S$. gregaria was removed and dissected to expose the myogenic bundle in the proximal region of the femur. The exposed bundle was bathed in about 10 $\mu \mathrm{l}$ of isotonic physiological locust saline (O'Shea and Adams, 1981), and $4 \mu \mathrm{l}$ aliquots of test solution (standards and muscle bath aliquots) in van Harreveld's physiological solution (van Harreveld, 1936) were applied to the muscle. The small movements of the tibia produced by the myogenic fibers were monitored with a photoelectric movement detector. After each $4 \mu \mathrm{l}$ sample application and response, the muscle was washed with about $5 \mathrm{ml}$ of locust saline and allowed to return to 
Figure 1. Tonic flexor system, which helps control graded changes in abdominal posture. Dorsal view of nerve cord and tonic flexor muscle from 1 hemisegment showing standard experimental arrangement. Numbers indicate the soma positions of the 6 motoneurons that innervate the muscle. Darkened somata, 1, 3, and 4, are immunoreactive with the proctolin antiserum (Bishop et al., 1984). The proctolin-immunoreactive excitatory motoneuron $\mathrm{fl}$ and the non-proctolin-immunoreactive excitatory motoneuron $\mathrm{f} 6$ are stimulated selectively from the connective and root, respectively. Neural activity is monitored in the tonic flexor root and muscle tension is recorded. One or 2 intracellular electrodes are also usually placed in muscle fibers. (Modified from Clement et al., 1983.)

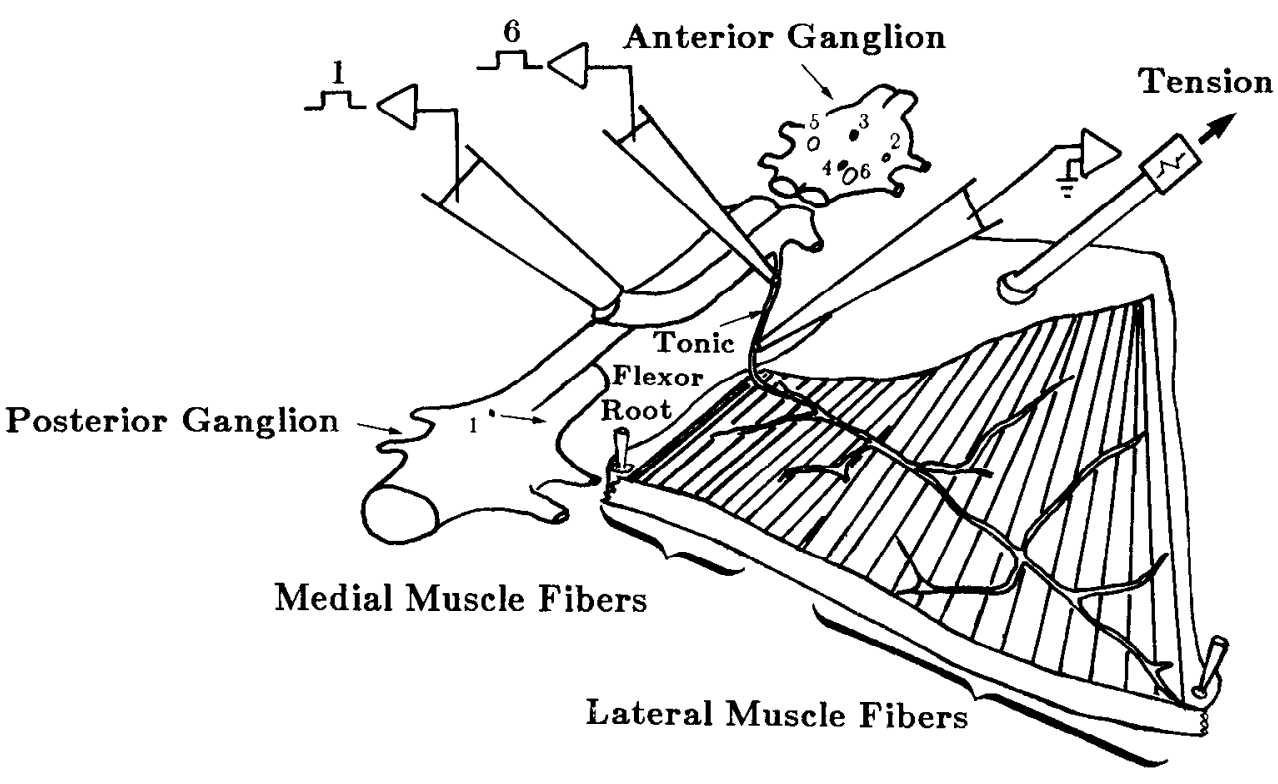

Some preparations were denervated 4 months prior to the experiment by exposing the motor root from the ventral side of the animal and severing the root as close to the muscle as possible. Long periods for denervation were necessary, since peripheral portions of cut crayfish motor axon degenerate very slowly. After 4 months, however, miniature endplate potentials could no longer be detected in muscle fibers. In such denervated preparations, tension leveled off within $10 \mathrm{~min}$ after exposure to high $(3.2 \times$ normal) $\mathrm{KCl}$-containing saline, whereas innervated or reinnervated preparations continued to show a tension increase for over $30 \mathrm{~min}$. This was an additional criterion for accepting a muscle as denervated. (The slow leveling of tension in innervated preparations may be due to the continuous, gradual release of neurotransmitter from presynaptic sites in response to the elevated $\mathrm{KCl}$ in the saline.)

Experimental procedures. Motor axons were stimulated and recorded with suction electrodes. Selective stimulation of the proctolin-immunoreactive motoneuron $\mathrm{fl}$ could be achieved by stimulating the connective posterior to the tonic flexor motor root, since $\mathrm{fl}$ is the only tonic flexor motoneuron with an axon in the posterior connective. Selective stimulation of the non-proctolin-immunoreactive excitatory motoneuron $\mathrm{f} 6$ was possible because it has the largest-diameter axon and hence the lowest firing threshold among the motoneurons (Fig. 1).

Mcchanical tension of the whole muscle was recorded with a strain gauge transducer comprising 2 symmetrically mounted strain gauges (BLH Electronics) and a Wheatstone bridge. Muscles were mounted under enough tension (about $75 \mathrm{mg}$ ) to take up any slack. This level was then taken as the baseline, or resting tension. Conventional techniques were used for recording intracellularly from muscle fibers with microelectrodes ( $3 \mathrm{M} \mathrm{KCl} ; 10-20 \mathrm{M} \Omega$ ). In some studies involving $\mathrm{fl}$ stimulation, the more lateral muscle fibers were dissected away. These fibers are not innervated by $\mathrm{fl}$, and since they add drag to the muscles that are, their removal greatly enhanced the amount of tension that was generated (Velez and Wyman, 1978a).

Appropriate concentrations of proctolin (Sigma) were made from a stock solution of $10^{-3} \mathrm{M}$. In some experiments, the preparation was continuously superfused with solutions at a rate of $8.2 \mathrm{ml} / \mathrm{min}$, while in others, the preparation was washed with at least $100 \mathrm{ml}$ of solution just prior to experimentation. In the timed EPSP study in Figure $3 A$, the $1 \mathrm{ml}$ bath was perfused with $10 \mathrm{ml}$ of control or proctolin-containing saline at a rate of $15 \mathrm{ml} / \mathrm{min}$. Experiments were originally performed at $14^{\circ} \mathrm{C}$, which corresponds to the temperature most commonly cited in the tonic flexor muscle literature. Similar results, however, were obtained at room temperature $\left(21^{\circ} \mathrm{C}\right.$ ). (Only small differences in magnitude were noted at the higher temperature.) For convenience, therefore, experiments requiring lengthy recording periods without accompanying perfusion were performed at room temperature. Thus, the data in Figures $2 B-5$ were obtained at room temperature.

For experiments on release, a Vaseline well was constructed around the preparation so that the solution bathing the muscle could be reduced to $75 \mu \mathrm{l}$. The preparation was occasionally washed with fresh crayfish 


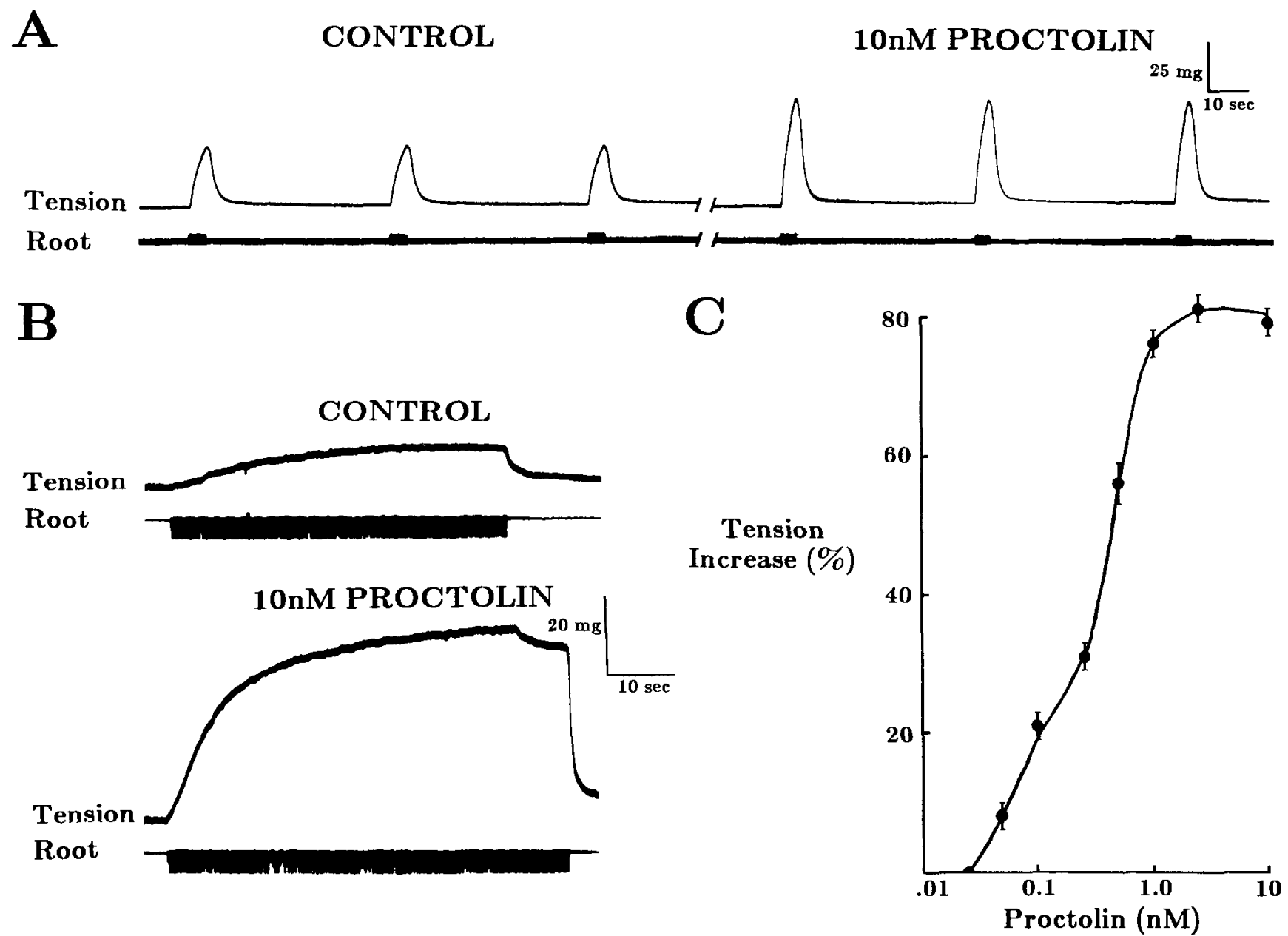

Figure 2. Superfused proctolin enhances neurally induced tension. A, Effects of bath-applied proctolin on short-duration, f1-evoked tension. Proctolin almost doubled the tension developed in response to a $4 \mathrm{sec}, 40 \mathrm{~Hz}$ train of motor impulses without changing the duration of the tension or affecting resting tension. $B$, Effects of bath-applied proctolin on long-duration, $[1$-evoked tension. Proctolin more than quadrupled the maximum tension achieved by stimulation at $16.7 \mathrm{~Hz}$. Most of the increase occurred in the first $50 \mathrm{sec}$. $C$, Dose-response curve for the effect of proctolin on muscle tension as measured in $A$ ( $n=3$ for each point).

saline by raising the level of fresh saline maintained in the surrounding dish above the Vaseline well while perfusing it with $100 \mathrm{ml}$. Neurons were selectively stimulated for $5 \mathrm{~min}$ at $10 \mathrm{~Hz}$. Four microliters of the $75 \mu l$ bath were removed near the muscle fibers before and after neural stimulation and applied immediately to the locust bioassay.

\section{Results}

Increased tension produced by superfused proctolin

When synthetic proctolin was added to the bath in nanomolar concentrations, it enhanced neurally induced tension increases in the tonic flexor muscles. In the experiment shown in Figure $2 A$, motoneuron $\mathrm{fl}$ was stimulated at $45 \mathrm{sec}$ intervals with 4 sec bursts at $40 \mathrm{~Hz}$. In the control condition, each burst produced a peak tension of $30 \mathrm{mg}$ above baseline. The effect of proctolin $\left(10^{-8} \mathbf{M}\right)$ had 3 notable features. First, it had no effect on resting muscle tension: the baseline was not reset after proctolin was added to the bath. Second, it increased the rate of tension increase, so that the amount of tension after $4 \mathrm{sec}$ of stimulation had reached $53 \mathrm{mg}$, an increase of $77 \%$. Finally, the duration of tension was not increased by proctolin, because the initial stage of the falling phase was faster in proctolin.

The effect of proctolin was even more dramatic when longer periods of stimulation were used. An example in which moto- neuron $\mathrm{fl}$ was stimulated at $16.7 \mathrm{~Hz}$ until a plateau level of tension was reached is shown in Figure $2 B$. In the control condition, a plateau of $9 \mathrm{mg}$ was obtained after $148 \mathrm{sec}$ of neural stimulation. In $10^{-8} \mathrm{M}$ proctolin, this same length of stimulation produced $39 \mathrm{mg}$ of tension, a $333 \%$ increase, due largely to a dramatic increase in the rate of tension development within the first $50 \mathrm{sec}$ of neural stimulation. (A tension plateau was not reached in this preparation, even after $240 \mathrm{sec}$ of stimulation, at which point tension began to deteriorate for unknown reasons.)

A dose-response curve for the proctolin effect, as measured in Figure $2 A$, is shown in Figure $2 C$. Threshold for the response was $5 \times 10^{-11} \mathrm{M}$ proctolin, with the maximum effect occurring at $2.5 \times 10^{-9} \mathrm{M}$ proctolin. Desensitization of the response occurred after proctolin concentrations reached $5 \times 10^{-8} \mathrm{M}$.

The time course of the response of superfused proctolin was estimated in the following way. The neuromuscular preparation was maintained in a $1 \mathrm{ml}$ bath. The bath volume was changed 10 times in the course of $40 \mathrm{sec}$ with either control saline or saline containing $10^{-8} \mathrm{M}$ proctolin. The motoneuron was stimulated for $3 \mathrm{sec}$ at $33.3 \mathrm{~Hz} 1 \mathrm{~min}$ after the start of the saline perfusion and each min thereafter, until no tension change could be detected. Figure $3 A$ shows the results of this experiment. 


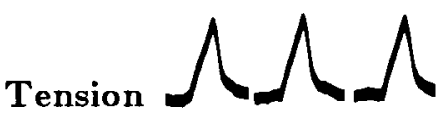
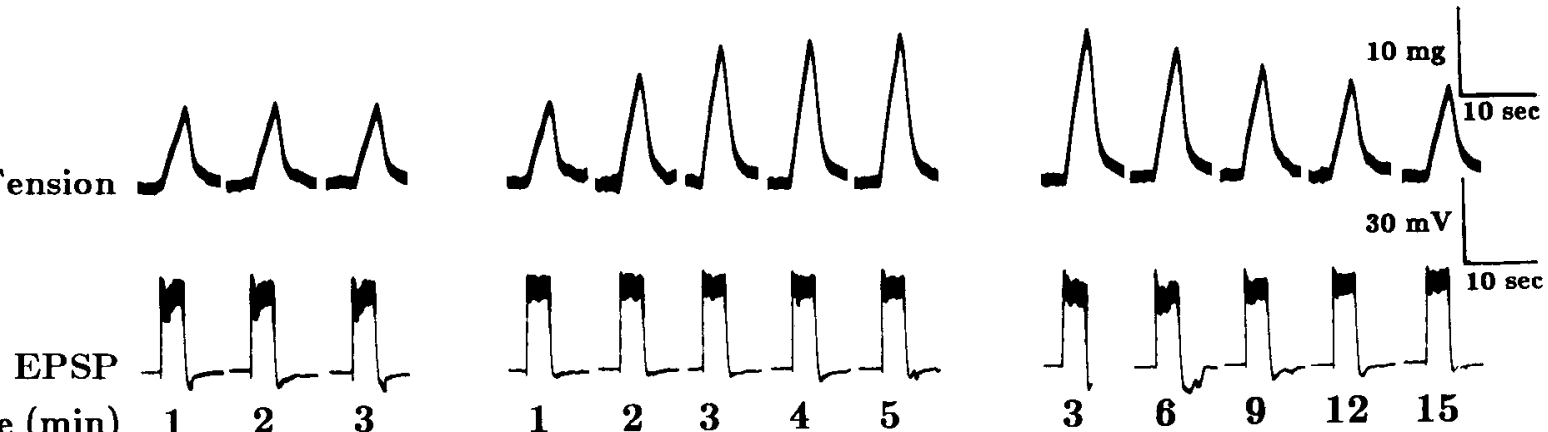

Time (min) $1 \quad 2 \quad 3$

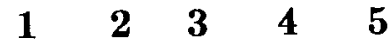

$\begin{array}{lllll}3 & 6 & 9 & 12 & 15\end{array}$
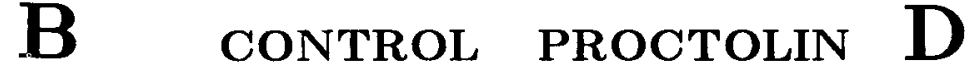

CONTROL

PROCTOLIN
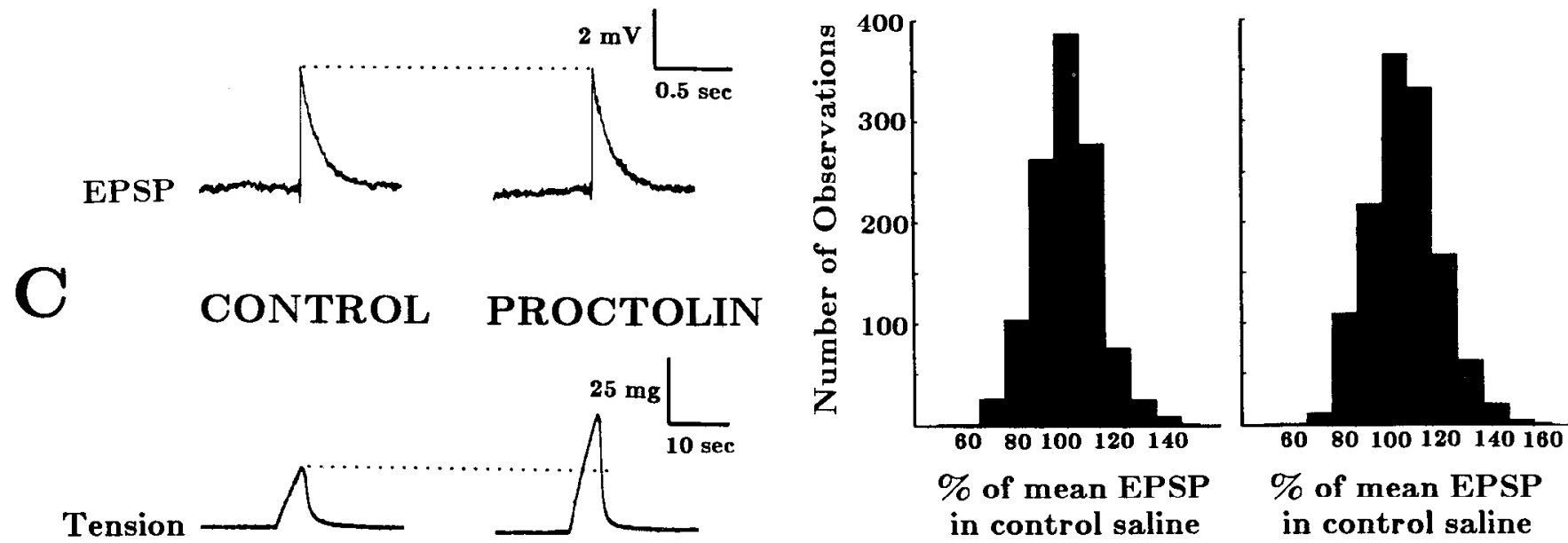

Figure 3. Absence of presynaptic proctolin effect for motoneuron $\mathrm{f} 1 . \mathrm{A}$, Effect of proctolin perfusion on $\mathrm{f} 1$-evoked ( $3 \mathrm{sec}$ stimulation at $33.3 \mathrm{~Hz}$ tension (top trace) and summated EPSPs (bottom trace). Tension doubled after $5 \mathrm{~min}$ in proctolin. The proctolin effect was eliminated after 15 min in wash. No detectable change in EPSPs occurred with either proctolin application or wash. $B$, Example of an experiment comparing unfacilitated EPSPs (generated by a $0.5 \mathrm{~Hz}$ stimulus) before and after application of saturating amounts of proctolin. EPSPs in proctolin appeared identical in shape and size to control EPSPs. However, tension produced by a $5 \mathrm{sec}, 40 \mathrm{~Hz}$ stimulus in the same preparation $(C)$ was doubled in the presence of proctolin. $D$, Results from 13 experiments (100 EPSPs each) showing amplitudes of unfacilitated EPSPs in control and proctolin-containing salines. Values were normalized as percentages of the mean EPSP amplitude in control saline. Mean EPSP amplitude in control saline: $100 \pm 13 \%$; in proctolin: $104 \pm 14 \%$.

Application of $10^{-8} \mathrm{M}$ proctolin produced a gradual increase in tension, which peaked at $5 \mathrm{~min}$ and was eliminated $12 \mathrm{~min}$ after washing with control saline.

\section{Normal EPSPs during superfusion}

In insects, proctolin acts postsynaptically (Adams and O'Shea, 1983). To determine proctolin's site of action in our crayfish preparation, we looked first at the summated EPSPs associated with the tensions generated in the time-course experiment described in Figure $3 A$. We found no apparent change in EPSP amplitude that could account for the change in tension.

This same conclusion was reached when we compared EPSP amplitudes in response to $0.5 \mathrm{~Hz}$ stimulation of the $\mathrm{f} 1$ motoneuron in control saline to those obtained in $5 \times 10^{-9}-10^{-8} \mathrm{M}$ proctolin saline, in which the proctolin response is saturated. In these studies, only the 9 most medial muscle fibers were used; more lateral fibers, which are not generally innervated by $\mathrm{fl}$ (Velez and Wyman, 1978a), were removed. Experiments were performed on 7 of the 9 remaining fibers. Figure $3 D$ summarizes the results of 13 experiments. The proctolin condition did not differ significantly from the control condition (2-tailed $t$ test; $p=0.76)$. The shape of the EPSP was also unchanged by proctolin (Fig. 3B). Since the low frequency of stimulation used in these experiments produced no measurable tension, the occurrence of proctolin-enhanced tension was confirmed for each preparation using a $40 \mathrm{~Hz}, 5 \mathrm{sec}$ stimulation (Fig. $3 \mathrm{C}$ ).

Proctolin amplifies tension increases in depolarized denervated muscles without affecting membrane resting potential

The lack of any major effect of proctolin on EPSPs is a good indication that proctolin is acting postsynaptically in this system, even though we fail to see a proctolin effect on resting muscle tension. To test this further, we applied proctolin to denervated muscle fibers. As shown in Figure $4 A$, proctolin had no effect on a resting, denervated muscle, but when the muscle was depolarized with high- $\mathrm{KCl}(3.2 \times$ the normal concentration $)$ saline to produce a sustained tension $23 \mathrm{mg}$ above resting tension, the addition of $10^{-6} \mathrm{M}$ proctolin caused a dramatic tension 
A
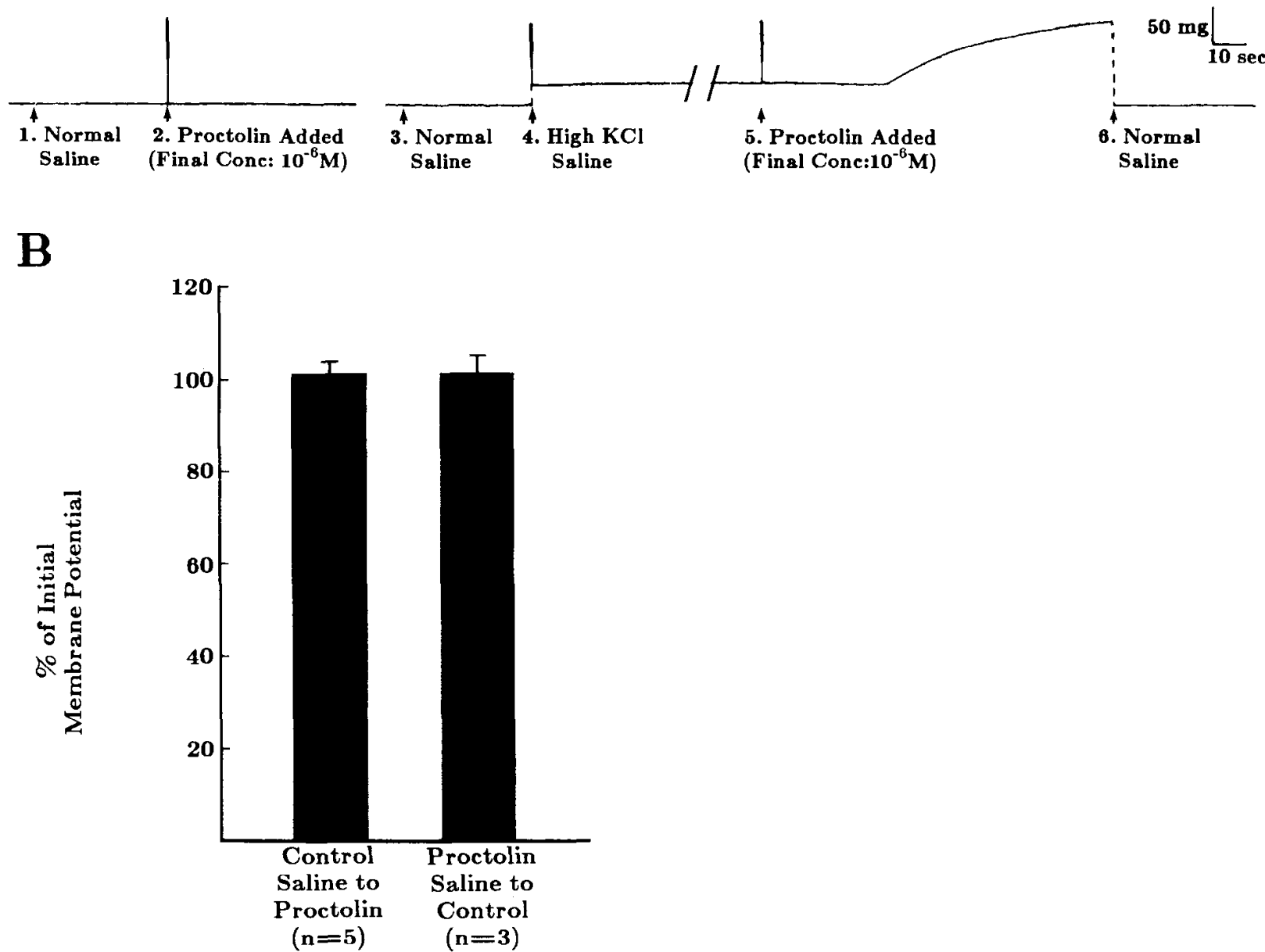

Figure 4. Postsynaptic action of bath-applied proctolin. A, Tension response of denervated tonic flexor muscle to bath-applied proctolin: 1 , in normal saline; 2 , in normal saline with proctolin; 3 , in normal saline; 4 , in high $(3.2 \times$ normal)-KCl saline; 5 , in high-KCl saline with proctolin; 6 , after wash in normal saline. $B$. Proctolin $\left(10^{-8} \mathrm{M}\right)$ produced no observable change in membrane potential after 5 min (first bar); membrane potentials were unchanged 15 min after proctolin was washed from the bath (second bar). Values are normalized as percentages of the initial membrane polential.

increase. In addition to its large amplitude, the increase was notable for its slow time course, consistent with the time course of proctolin activity in normal innervated preparations (Fig. $3 A)$.

It is consistent with these results that proctolin did not depolarize the resting membrane potential (Fig. $4 B$ ). In 7 separate muscle fibers, the resting membrane potential was measured either before and $5 \mathrm{~min}$ after perfusion of $10^{-8} \mathrm{M}$ proctolin (Fig. $4 B$, first bar; $n=5$ ) or before and 15 min after the same amount of proctolin had been washed from the preparation (Fig. $4 B$, second bar; $n=3$ ). Membrane potentials were not significantly changed with either procedure. Membrane potentials in these experiments ranged between -80 and $-110 \mathrm{mV}$.

We can summarize the above results as follows: superfused proctolin acts postsynaptically to potentiate tension in a depolarized muscle. Proctolin alone does not change the resting potential of the muscle nor produce tension. In the next section, we show that proctolin is released from motoneurons in response to nerve impulses.

\section{Proctolin release by neuronal stimulation}

We previously used a proctolin bioassay combined with HPLC to demonstrate the presence of proctolin in homogenates of the tonic flexor muscle (Bishop et al., 1984). We determined in that study that all bioactivity in the homogenate was due to proctolin. In the present study, we used the bioassay to monitor release of the peptide in response to selective stimulation of proctolinimmunoreactive motoneurons. We used the response to an identical stimulation of a non-proctolin-immunoreactive motoneuron, f6, as a control.

The unique features of motoneuron $\mathrm{fl}$ (proctolin-immunoreactive) and motoneuron $\mathrm{f} 6$ (non-proctolin-immunoreactive) that were described in Materials and Methods allowed us to stimulate them selectively and separately, while monitoring for proctolin release with the bioassay. Evidence for proctolin release from $\mathrm{fl}$ is shown in Figure $5 \mathrm{~A}$. Application of a bath aliquot (upward arrow) from a resting muscle produced little increase in the frequency of the bioassay's myogenic rhythm. However, when a bath aliquot was taken immediately after $\mathrm{fl}$ stimulation at $10 \mathrm{~Hz}$ for $5 \mathrm{~min}$ (which is well within the range of the tonic activity for $f($ in an unstimulated, isolated abdomen), it produced an increase in the myogenic rhythm that was qualitatively indistinguishable from that of authentic proctolin.

In Figure $5 B$, bioactivity is expressed in terms of a bioassay ratio that reflects an increase in myogenic rhythm as a number greater than 1 (see Materials and Methods for details). In this 


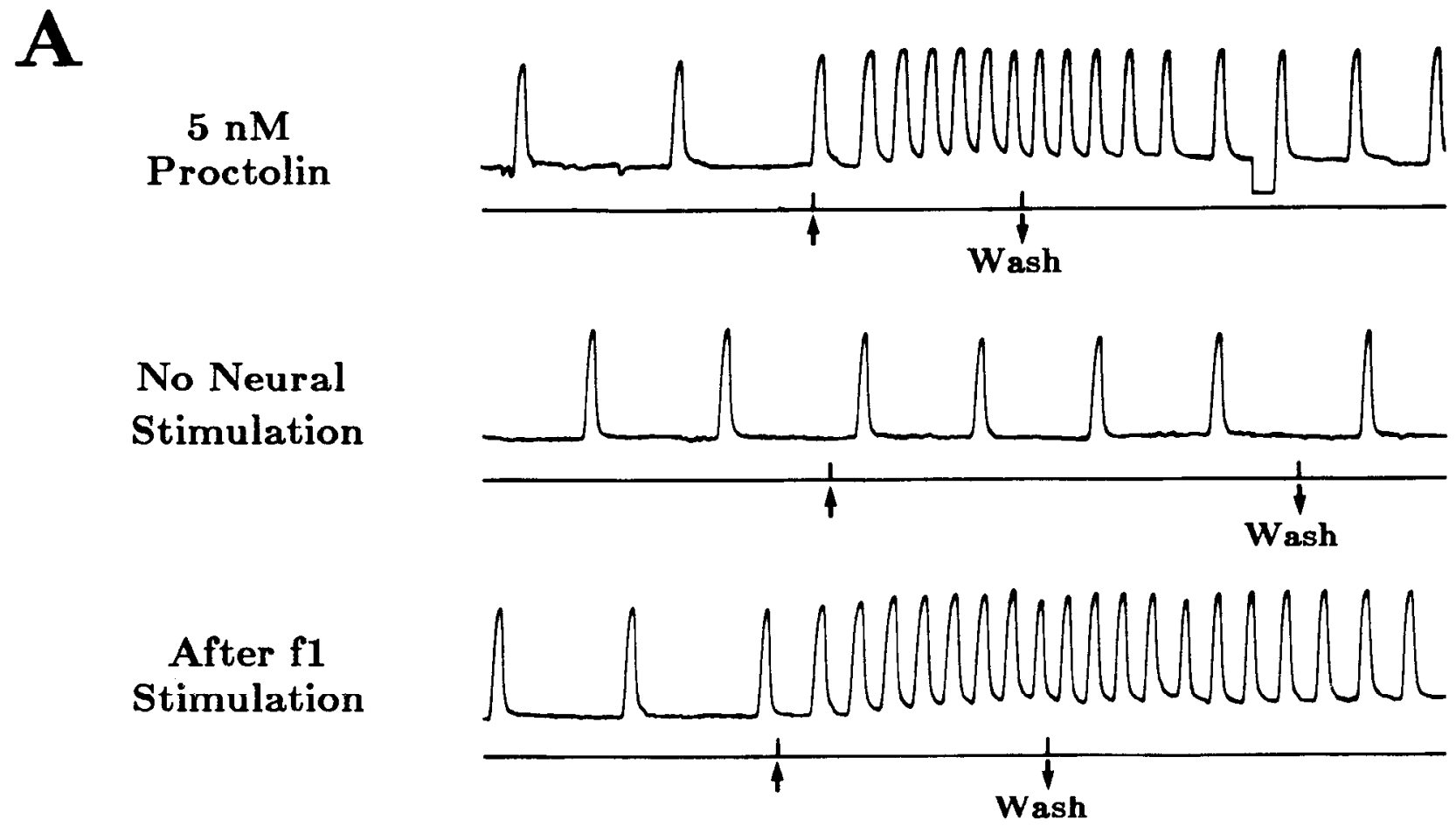

\section{B f1 vs. f6 Stimulation $\quad \mathrm{C}$ Sequential Stimulation of $\mathrm{f} 1$}
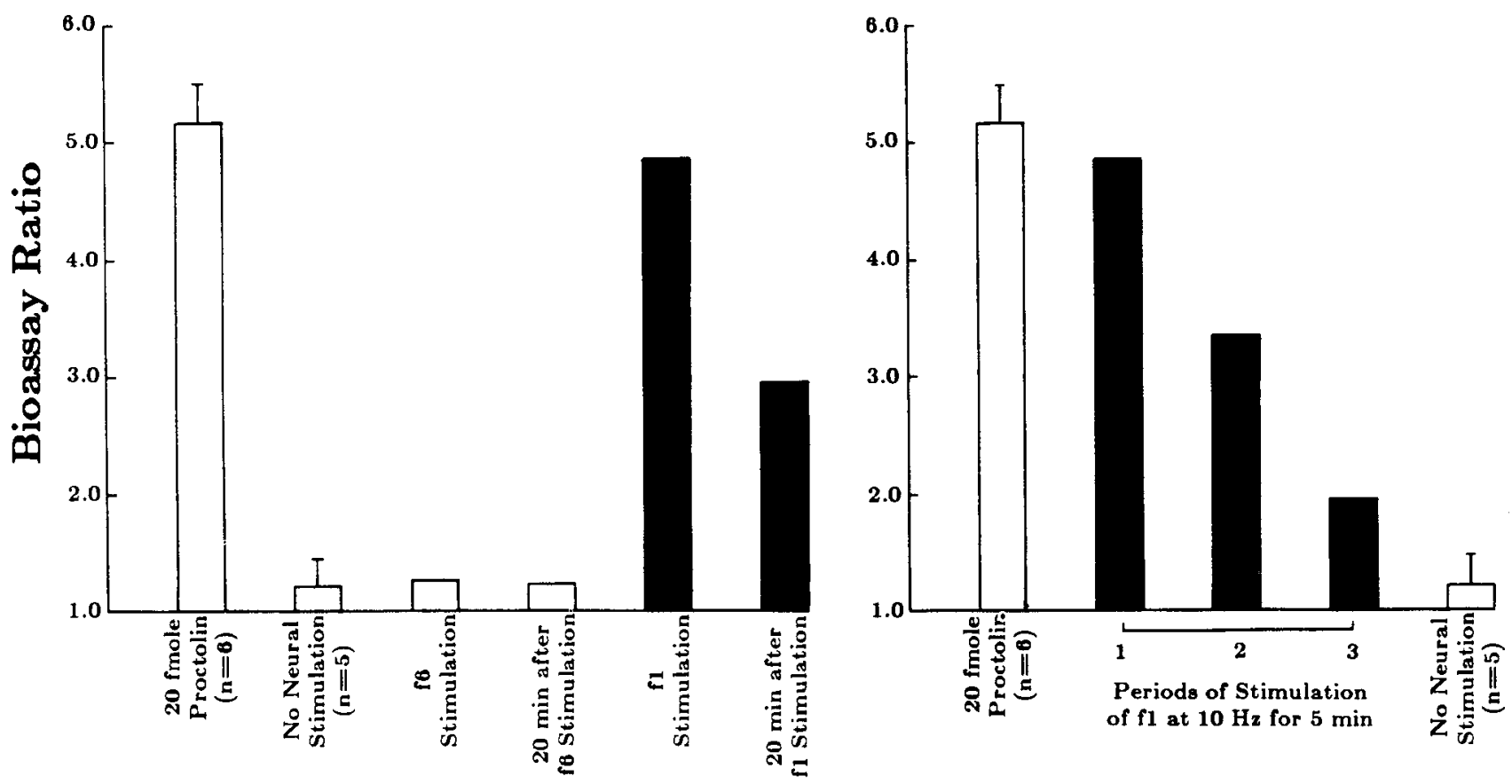

Figure 5. Proctolin release and depletion by neural stimulation. A, Response of the locust extensor tibiae binassay to a $4 \mu$ l aliquot of $5 \times 10^{-9}$ $\mathrm{M}$ proctolin (top), to an aliquot from the resting muscle bath (middle), and to an aliquot from the muscle bath after 5 min of f1 stimulation at 5 $\mathrm{Hz}$ (bottom). Upward arrows indicate aliquot application; downward arrows indicate bioassay wash. $B$, Comparison of bioassay response to bath aliquots after stimulation of the non-proctolin-immunoreactive motoneuron f6 (open bars without error bars) and after stimulation of the proctolinimmunoreactive motoneuron $\mathrm{fl}$ (solid bars). Motoneurons were stimulated at $10 \mathrm{~Hz}$ for $5 \mathrm{~min}$. $C$, Bioactivity in response to 3 sequential periods of stimulation of the motoneuron $\mathrm{fl}$ at $10 \mathrm{~Hz}$ for $5 \mathrm{~min}$. Bioactivity significantly decreased after each period. 


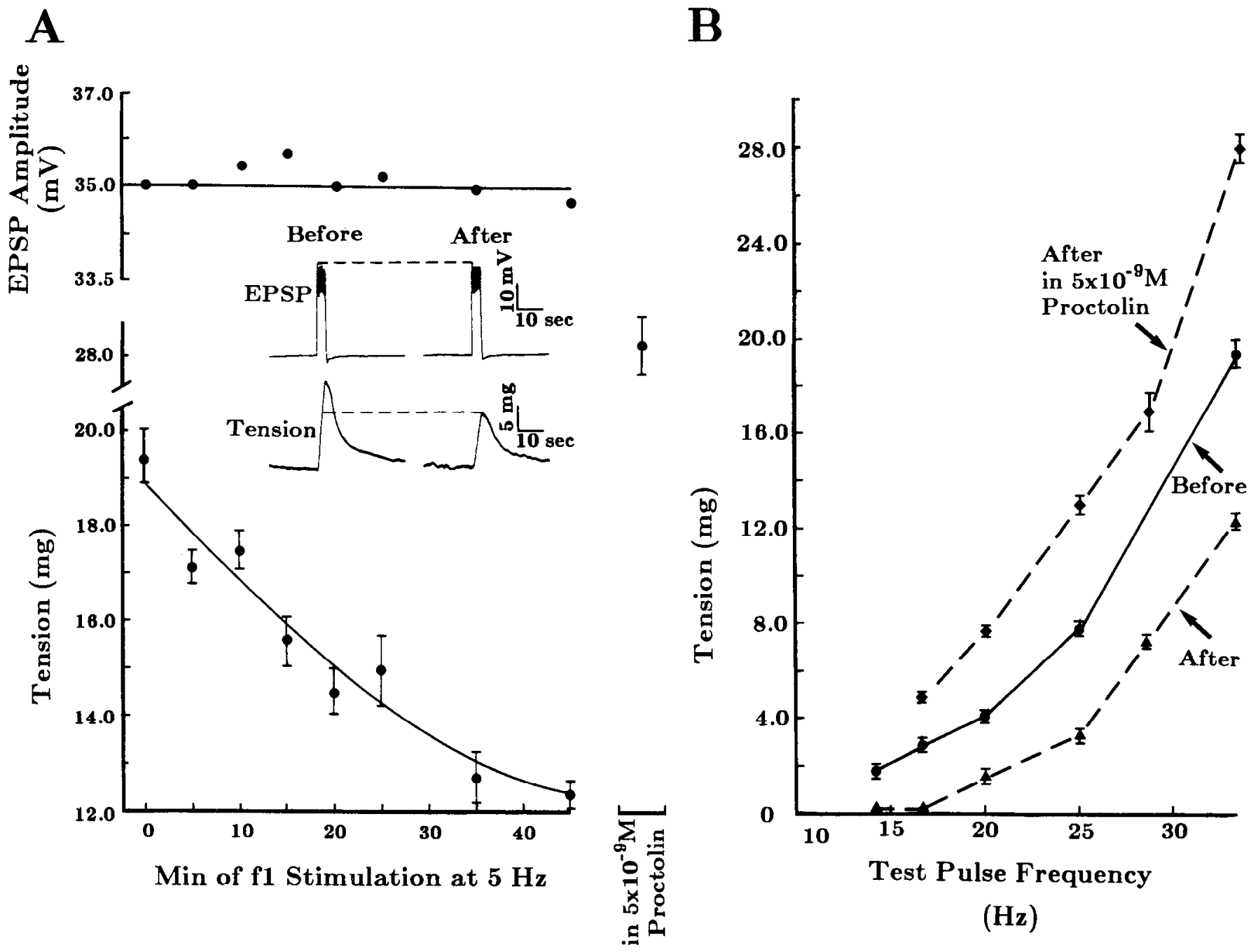

Figure 6. Use-associated tension reduction for proctolinergic motoneuron $\mathrm{fl}$. $A$, Plot of tension as a function of elapsed time of $5 \mathrm{~Hz}$ stimulation. Tension, in response to the $3 \mathrm{sec}, 33.3 \mathrm{~Hz}$ test stimulus, was gradually reduced as the amount of use ( $5 \mathrm{~Hz}$ stimulation) was increased (lower graph; $n=3$ for each point). EPSPs were unchanged (top graph; each point represents the averaged maximum EPSP amplitude of 3 trials). Tension was restored with the addition of proctolin to the bath. Inset: Example of tension and EPSP response before and after 45 min of f1 stimulation of 5 $\mathrm{Hz}$; EPSP amplitude was unchanged, but tension was reduced by $36 \%$. B. Use-associated tension reduction as a function of the test stimulus frequency in the same preparation used in $A$. Tension ( $n=3$ for each point) in response to 3 sec pulses was measured before 45 min of $5 \mathrm{~Hz}$ stimulation of $\mathrm{f} 1$ (solid line) and after stimulation in control saline (lower broken line) and $5 \times 10^{-9} \mathrm{M}$ proctolin-containing saline (upper broken line).

experiment, stimulation of motoneuron $\mathrm{f} 1$ produced a bioassay ratio approximately equivalent to $20 \mathrm{fmol}$ of proctolin. Identical stimulation of motoneuron f6 produced no significant change in the bioassay ratio. Twenty minutes after stimulation, the proctolin concentration in an aliquot taken from just above the muscle was still about half the original value-the decline was probably the result of diffusion away from the muscle. Thus, an efficient mechanism for inactivating or removing proctolin is lacking in our preparation.

Significant increases in bioactivity were detected in response to stimulation of motoneuron $\mathrm{fl}$ in each of the 4 experiments that were conducted. In a separate experiment, in which proctolinergic motoneurons $\mathrm{B}$ and $\mathrm{f} 4$ were stimulated, a significant increase was also detected. In no experiment $(n=3)$ was any significant increase in bioactivity due to proctolin release from f6 detected, even after several sequential stimulation periods.

The results shown in Figure $5 B$ allow us to estimate a lower limit for the amount of proctolin released per nerve impulse. In this experiment, bioactivity approximately equivalent to 4 $\mu \mathrm{l}$ of $5 \times 10^{-9} \mathrm{M}$ proctolin saline, or $20 \mathrm{fmol}$ of proctolin, was recovered after $5 \mathrm{~min}$ of stimulation at $10 \mathrm{~Hz}$, or 3000 nerve impulses. This gives $6.7 \times 10^{-18} \mathrm{~mol}$, or about $4 \times 10^{6}$ molecules, of proctolin per impulse. If each of the 40 muscle fibers has 10 terminals from $\mathrm{fl}$, then each terminal was releasing 10,000 molecules of proctolin per impulse. If the number of terminals is 100 per muscle fiber, the figure drops to 1000 molecules per impulse. These figures represent lower limits because it is unreasonable to assume that all released proctolin was recovered.

\section{Depletion of proctolin by repeated stimulation}

If the above release experiment is extended to include 2 additional periods of $\mathrm{f} 1$ stimulation separated by washes, the amount of proctolin-like bioactivity declines sharply after each subsequent period of stimulation (Fig. 5C). There was no apparent 
A

Proctolinergic f1

Non-Proctolinergic f6

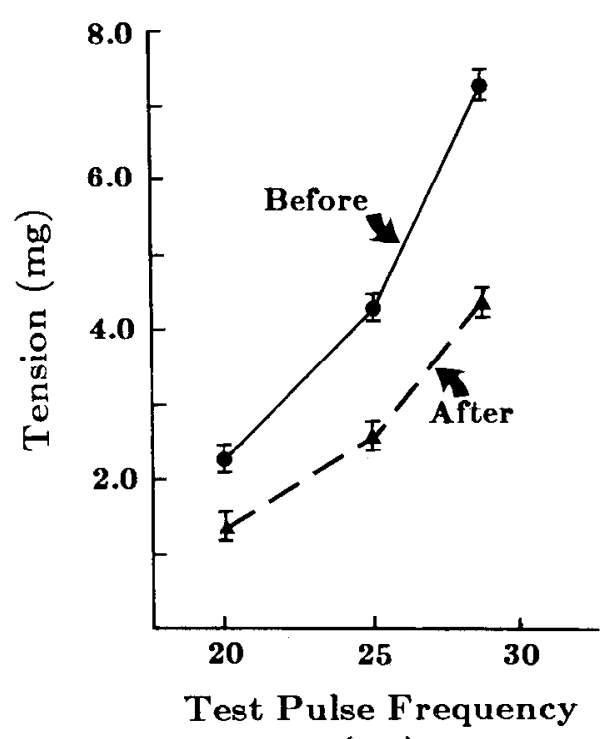

$(\mathrm{Hz})$

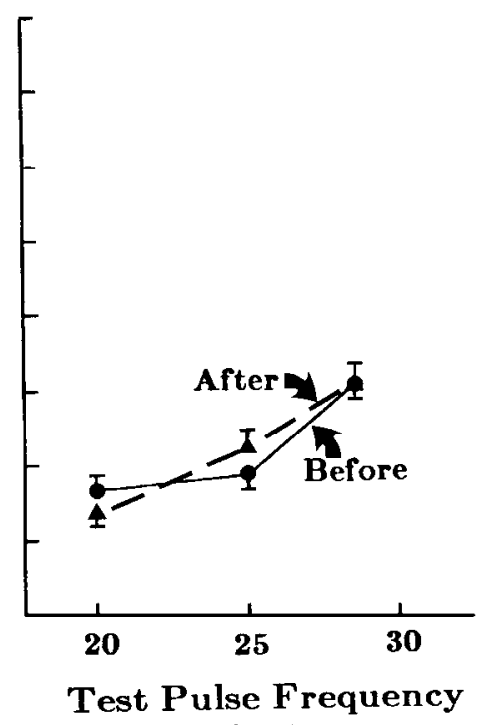

(Hz)

B

Figure 7. Absence of use-associated tension reduction for non-proctolinergic motoneuron $\mathrm{f} 6 . A$, Tensions generated by a $3 \mathrm{sec}$ stimulation of motoneuron $\mathrm{fl}$ differed significantly after $20 \mathrm{~min}$ of use $(5$ $\mathrm{Hz}$ stimulation) at each of the 3 test stimulus frequencies examined ( $n=3$ for each point). Tensions generated under identical circumstances by motoneuron $f 6$ were unchanged at each frequency. $B$, Tension and EPSP records (in response to $3 \mathrm{sec}$, $25 \mathrm{~Hz}$ test stimulus) for motoneurons $\mathrm{fl}$ and $f 6$ before and after a $20 \mathrm{~min}$ period of $5 \mathrm{~Hz}$ stimulation. EPSPs remained unchanged for both motoneurons; tension was decreased only for motoneuron $\mathrm{fl}$.

\section{Before \\ $20 \min$ of $\mathbf{f} 1$ \\ Stimulation \\ After \\ $20 \min$ of $\mathbf{f 1}$ \\ Stimulation}

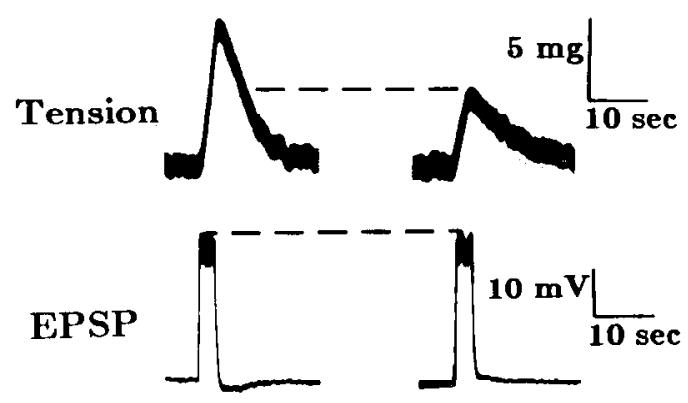

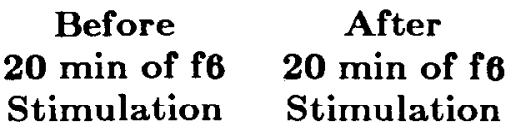
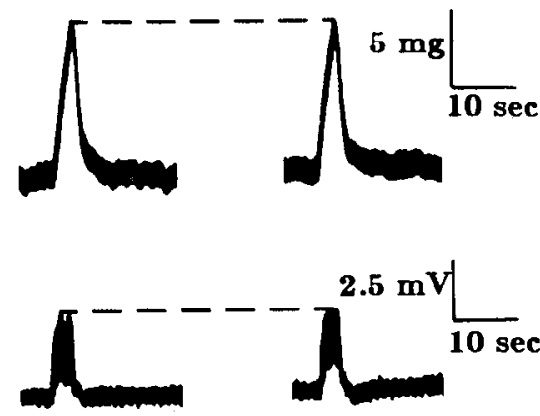

recovery from this reduction; levels were still low after $2 \mathrm{hr}$. Our interpretation of these results is that proctolin is being permanently depleted from the severed axons in response to stimulation. This interpretation is consistent with the idea that proctolin, like other peptide transmitters (Lundberg, 1981), is synthesized in the cell body and transported to the terminals for release. In contrast, conventional transmitters may be recycled by mechanisms located in the terminals and thus are not subject to use-associated depletion. Indeed, we found that the same paradigm that reduced proctolin release had no effect on conventional EPSPs. For example, as shown in Figure $6 A$ (upper graph), EPSPs retained normal amplitude even after $45 \mathrm{~min}$ of continuous stimulation at $5 \mathrm{~Hz}$, which evokes 27,000 impulses. This confirms previous conclusions concerning the stability of conventional neurotransmission in severed crayfish axons (Hoy et al., 1967; Bittner, 1977). Taken together, these results indicate that proctolin can be selectively depleted from the severed motor axon by stimulation, leaving the conventional neurotransmitter, as reflected in conventional EPSP amplitude, unchanged.

\section{Use-associated tension decreases}

Our results with superfused proctolin suggest that proctolin depletion should be accompanied by a decrease in the ability of the motoneurons to generate muscle tension. We tested the consequence of proctolin depletion on muscle tension with a preparation like the previous ones, except that the bath had a larger volume and was continuously perfused with fresh saline to prevent released proctolin from accumulating. Muscle tension and EPSPs were monitored simultaneously while stimulating fl for 5 min intervals at $5 \mathrm{~Hz}$. This lower frequency of stimulation was chosen for most experiments in order to avoid the larger muscle contractions that can dislodge the intracellular recording 

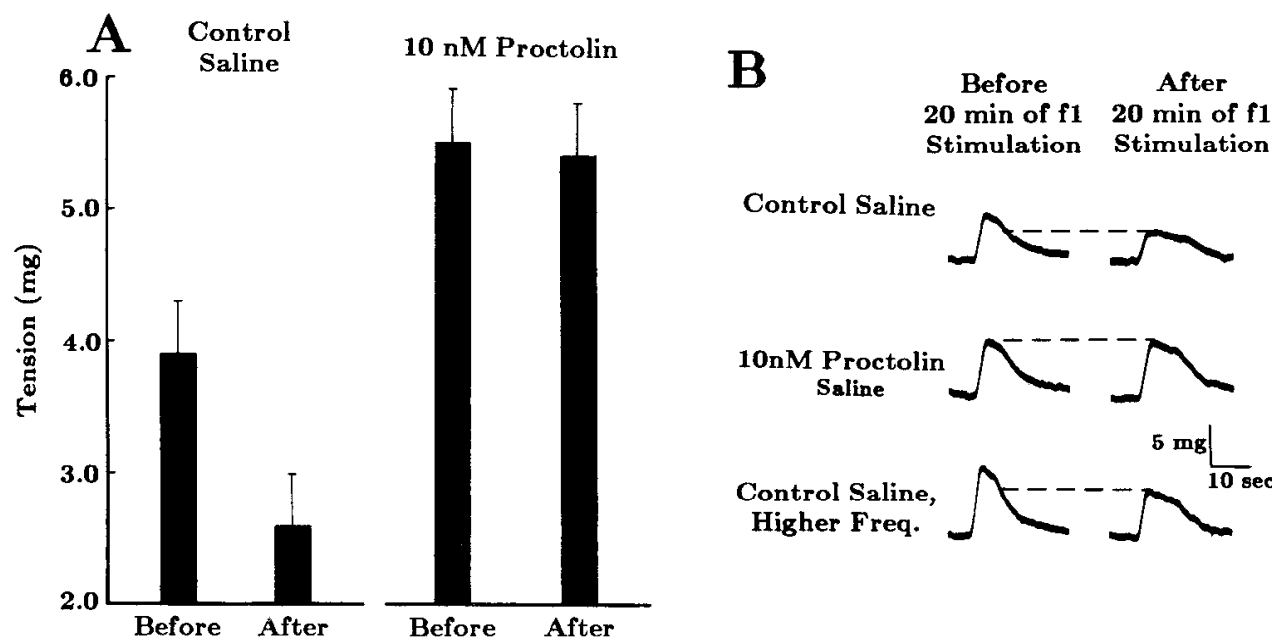

Control Saline
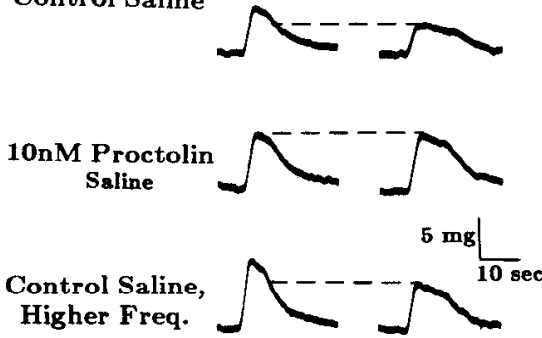

Figure 8. Absence of use-associated tension reduction in saturating amounts of proctolin. $A$, Magnitude of tension generated by a 3 sec, $31.8 \mathrm{~Hz}$ test stimulus, in control saline and $10^{-8} \mathrm{M}$ proctolin before and after $20 \mathrm{~min}$ of $\mathrm{f} 1$ stimulation at $5 \mathrm{~Hz}(n=3$ for each bar); a significant decrement in tension occurred only in control saline. $B$, Examples of tension generated by a 3 sec test stimulus, before and after 20 min of $f 1$ stimulation at $5 \mathrm{~Hz}$ at the same frequency $(25 \mathrm{~Hz}$ ) in control (top traces) and proctolin saline (middle traces), and at a higher frequency (28.6 Hz) in control saline (bottom traces). Use-associated tension reduction occurred for both frequencies in control saline, but not in saturating amounts of proctolin.

electrode; similar results were produced with $10 \mathrm{~Hz}$ stimulation. After each 5 min period of stimulation, the preparation was allowed to relax for about $5 \mathrm{~min}$ and was then stimulated with a $3 \mathrm{sec}$ train at $33.3 \mathrm{~Hz}$ to produce a facilitated and summated

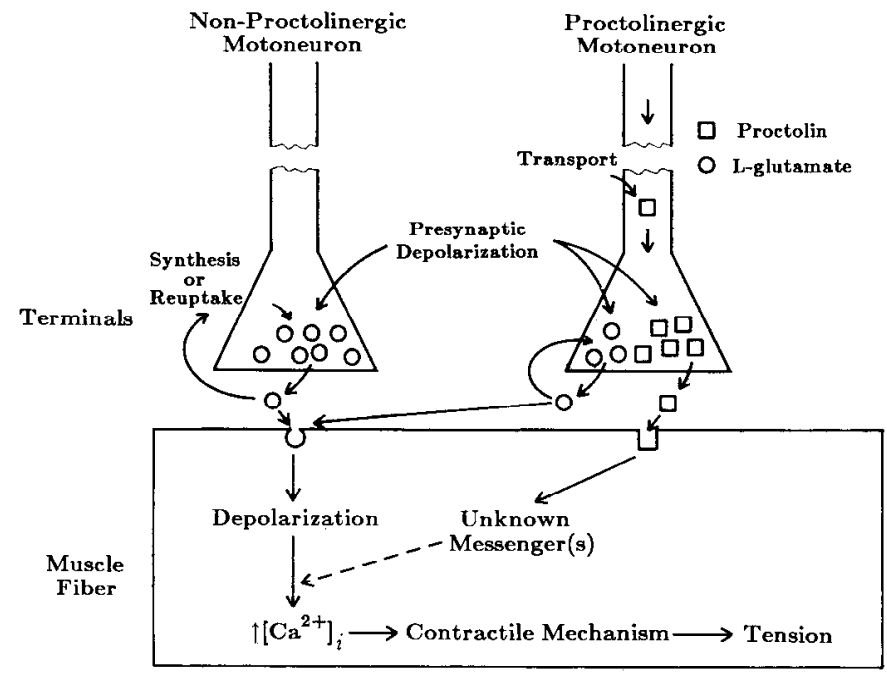

Figure 9. Summary of cotransmission in the crayfish tonic flexor motor system. Each muscle fiber is innervated by at least 1 non-proctolinergic motoneuron and 1 proctolinergic motoneuron, which also contain a conventional conductance-increasing transmitter. Both conventional and peptide transmitters are released in response to nerve impulses. The proctolin pool can be depleted from the severed motor axon by extended nerve stimulation, suggesting that the cellular machinery that supplies the peptide to the nerve terminal is incapacitated by the severing operation. The conventional neurotransmitter pool is undisturbed by extended nerve stimulation of the severed axon, suggesting that it continues to be replenished. Both transmitters act postsynaptically to promote tension generation in the muscle. Proctolin cannot depolarize the resting membrane potential and can only induce tension after depolarization by the conventional transmittter. Thus, proctolin serves to amplify tension generated by depolarization due to the conventional neurotransmitter. The mechanism underlying proctolin's amplification of tension is unknown. compound EPSP in the muscle and an associated tension increase, the peak amplitudes of which were measured. The first and last tension traces in the series are shown in the inset in Figure 6.4, together with their associated EPSPs and a plot of each measure as a function of elapsed time.

The results show a marked decline in the amplitude of muscle tension, with no change in tension duration or EPSP amplitide. (The same level of tension could still be elicited after $45 \mathrm{~min}$ by increasing the frequency of neural stimulation to $38 \mathrm{~Hz}$, which produced a significantly larger EPSP.) The time course of the decline is somewhat slower than that seen when proctolin release was measured (Fig. 5C), perhaps because of the lower rate of stimulation, which might be expected to give less depletion. Tension was restored in this experiment with the addition of proctolin (Fig. 6A, last point on lower graph).

Since the test stimulation frequency in the above experiment was at the high end of the physiological range, a series of frequencies, including some in the range seen during normal tonic activity $(\leq 20 \mathrm{~Hz})$, were examined before and after proctolindepleting activity (Fig. $6 \mathrm{~B}$ ). The drop in tension occurred at all frequencies and actually showed a more pronounced effect at the lower frequencies, where all measurable tension was eliminated. In all cases, tension was restored with the addition of proctolin. This experiment, in various forms, was repeated 10 times. In all cases, a significant tension reduction occurred during 20 min of activity, with no associated change in EPSP amplitude. No tension reduction occurred without stimulation. As with proctolin depletion, tension reduction was maintained for at least $2 \mathrm{hr}$.

If this decrease in tension is truly due to proctolin depletion, motoneurons without proctolin would not be expected to show similar use-associated decreases. Therefore, the same paradigm was applied to motoneuron $\mathrm{f} 6$, which does not contain proctolin, and the effects compared to those for $\mathrm{fl}$ in the same preparation (Fig. $7 \mathrm{~A}$ ). Tension produced by $\mathrm{f} 6 \mathrm{did}$ not decline significantly after $20 \mathrm{~min}$ of stimulation at $5 \mathrm{~Hz}$, while tension produced by fl did. Because of the differing amounts of tension produced by the 2 neurons, 3 different frequencies were used; a reduction in tension was seen at every frequency for $\mathrm{fl}$ and at no frequency 
for $\mathrm{f6}$. Figure $7 B$ shows the same results in a different experiment and also shows that the EPSPs are unchanged for each motoneuron. (Tension and EPSP measurements were taken before and after a $20 \mathrm{~min}$ period of $5 \mathrm{~Hz}$ stimulation. The experiment was performed in $5 \times 10^{-10} \mathrm{M}$ proctolin, which is a subsaturating amount, to allow the generation of approximately comparable levels of tension by the 2 motoneurons using the same stimulation frequency of $25 \mathrm{~Hz}$.)

Additional evidence that the decline in tension is due to the depletion of proctolin, rather than to postsynaptic factors such as desensitization or a decline in excitation-contraction coupling, was obtained by repcating the stimulation paradigm whilc bathing the muscle in $10^{-8} \mathrm{M}$ proctolin, which is a saturating dose. There was no significant reduction in tension under this condition (Fig. $8 A$ ). Figure $8 B$ shows the same result in a separate experiment, and also shows that proctolin has not saturated the muscle's ability to produce tension, since greater, activity-reducible tension can be generated in control saline by stimulation at a higher frequency.

\section{Discussion}

The present and previous results lead to the following conclusions about the role of proctolin in this system. Proctolin is synthesized in the cell bodies of 3 of the 5 motoneurons and transported down their axons to the neuromuscular terminals, where it is released by nerve impulses. Every muscle fiber in the system receives input from at least 1 proctolinergic neuron, as well as from at least 1 non-proctolinergic neuron. The same neurons that release proctolin also release a conventional neurotransmitter, which produces conductance-increasing, depolarizing EPSPs in the muscle fibers. Proctolin alone has no detectable effect on muscle membrane potential or tension, nor does it, for at least 1 excitatory motoneuron, affect conventional synaptic transmission. Instead, it affects some stage of the excitation-contraction coupling mechanism to markedly amplify the tension generated by a given level of depolarization. We do not know the cellular mechanism of proctolin's action, but since the peptide is incapable of initiating tension in a resting muscle, it presumably acts by amplifying the effects of depolarization. (See summary in Fig. 9). There is no efficient mechanism for inactivating or removing proctolin in our preparation. This is probably due to the removal of the serum, where inactivating enzymes for proctolin have been detected in other systems (Steele and Starratt, 1985). In the intact preparation, neurally-released proctolin is probably rapidly inactivated.

To generate muscle tension in this system, there is an absolute requirement of depolarization beyond the resting level. Only the conductance-increasing EPSPs of the conventional neurotransmitter can therefore initiate tension, and a cessation of conventional neurotransmission causes tension to drop rapidly to zero, even in the presence of large amounts of proctolin. Thus, conventional neurotransmission exerts exclusive control over tension onset and offset, while proctolin and the conventional neurotransmitter jointly determine the magnitude of tension.

What, then, do these results suggest about the functional significance of dual transmission in this system? Here, proctolin appears to meet a need for efficient production of tension by providing a means of generating tension with less neural activity. A given motoneuron in this system may fire 1 million impulses/d; thus, the use of proctolin seems particularly adaptive.

Postural muscles, such as these, must maintain a given po- sition for long periods, but also need to adjust rapidly to changing conditions. Proctolin's greatest contribution is probably to maintained tension, since the peptide's response reaches a maximum only after tens of seconds (Fig. $2 B$ ). However, short-term stimulations ( $3 \mathrm{sec}$ and less) were also significantly amplified by the peptide (Fig. $6 B$ ) and an effect of proctolin on rapid postural abdominal adjustments involving the use of these muscles has not been ruled out.

The above description of proctolin's action differs from that of its action in insects, where proctolin causes tension increases in resting muscle fibers and prolongs the tension produced by neural stimulation (Adams and O'Shea, 1983). Both of the differences can be simply explained by assuming that insect muscles are somewhat depolarized relative to crayfish muscles, or that the depolarization-tension curve is shifted. In the crayfish muscle, tension requires that the muscle be depolarized from the rest potential. Hence, the duration of tension is set by the stimulus duration and time constant of the membrane. When a muscle achieves more tension for a given level of depolarization, the initial stage of the falling phase will be faster in proctolin, as was seen in Figure 2.

In summary, our results indicate that proctolin in the crayfish tonic flexor nerve-muscle preparation is an important secondary neurotransmitter and a contributor to the magnitude of tension generated by the depolarization of the conventional neurotransmitter. The preparation used in this study may henceforth serve as an excellent model system for understanding the coordination of multiple transmitters.

\section{References}

Adams, M. E., and M. O'Shea (1983) Peptide co-transmitter at neuromuscular junction. Science 221: 286-289.

Bishop, C. A., J. J. Wine, and M. O'Shea (1984) Neuropeptide proctolin in postural motoneurons of the crayfish. J. Neurosci. 4: 20012009.

Bittner, G. D. (1977) Trophic interactions of crustacean neurons. In Identified Neurons and Behavior of Arthropods, G. Hoyle, ed., pp. 507-532, Plenum, Ncw York.

Clement, J. F., A. K. Taylor, and S. J. Velez (1983) Effects of a limited target area on regeneration of specific neuromuscular connections in the crayfish, J. Neurophysiol. 49: 216-226.

Evoy, W. H., and R. Beranek (1972) Pharmacological localization of excitatory and inhibitory synaptic regions in crayfish slow abdominal flexor muscle fibers. Comp. Gen. Pharmacol. 3: 178-186.

Futamachi, K. J. (1972) Acetylcholine: Possible neurotransmitter in crustacea. Science 175: 1373-1375.

Hildebrand, J. G., J. G. Townsel, and E. A. Kravitz (1974) Distribution of acetylcholine, choline, choline acetyltransferase, and acetylcholinesterase in regions and single identified axons of the lobster nervous system. J. Neurochem. 23: 951-963.

Hoy, R. R., G. D. Bittner, and D. Kennedy (1967) Regeneration in crustacean motoncurons: Evidence for axonal fusion. Science 156: 251-252.

Kennedy, D., and K. Takeda (1965) Reflex control of abdominal flexor muscles in the crayfish. II. The tonic system. J. Exp. Biol. 43: 229246.

Keshishian, H., and M. O'Shea (1985) The distribution of a peptide neurotransmitter in the postembryonic grasshopper central nervous system. J. Neurosci. 5: 992-1004.

Lundberg. J. M. (1981) Evidence for coexistence of vasoactive intestinal polypeptide (VIP) and acetylcholine in neurons of cat exocrine glands. Acta Physiol. Scand. 112: 1-57.

O'Shea, M., and M. E. Adams (1981) Pentapeptide (proctolin) associated with an identified neuron. Science 213: 567-569.

O'Shea, M., and C. A. Bishop (1982) Neuropeptide proctolin associated with an identificd skeletal motoneuron. J. Neurosci. 2: 1242 1251 . 
Otsuka, M., L. L. Iversen, Z. W. Hall, and E. A. Kravitz (1966) Release of gamma-aminobutyric acid from inhibitory nerves in lobster. Proc. Natl. Acad. Sci. USA 56: 1110-1115.

Steele, R. W., and A. N. Starratt (1985) In vitro inactivation of the insect neuropeptide proctolin in haemolymph from Periplaneta americana. Insect Biochem. 15: 511-519.

van Harreveld, A. (1936) A physiological solution for freshwater crustaceans. Proc. Soc. Exp. Biol. Med. 34: 428-432.

Velez, S. J., and R. J. Wyman (1978a) Synaptic connectivity in a crayfish neuromuscular system. I. Gradient of innervation and synaptic strength. J. Neurophysiol. 41: 75-84.

Velez, S. J., and R. J. Wyman (1978b) Synaptic connectivity in a crayfish neuromuscular system. II. Nerve-muscle matching and nerve branching patterns. J. Neurophysiol. 41: 85-96.

Wine, J. J., J. E. Mittenthal, and D. Kennedy (1974) The structure of tonic flexor motoneurons in crayfish abdominal ganglia. J. Comp. Physiol. 93: 315-335. 